\title{
Micropropagation of Lowbush Blueberry from Mature Field-grown Plants
}

\section{Line Brissette, Laurence Tremblay ${ }^{1}$, and Daniel Lord ${ }^{2}$ Département des Sciences Fondamentales, Université du Québec à Chicoutimi, Chicoutimi, Qué G7H 2B1, Canada}

Additional index words. tissue culture, rejuvenation, in vitro, Vaccinium angustifolium, rooting

\begin{abstract}
Bud cultures from nonjuvenile field clones of lowbush blueberry (Vaccinium

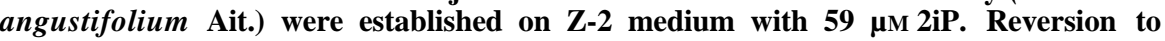
juvenile characteristics with small and rounder leaves occurred only on two explants after 19 weeks in culture. These shoots grew vigorously and could be easily subcultured. The number of shoots of one clone doubled every 23.3 days. Reducing the $2 \mathrm{iP}$ concentration to 12.3 and $24.6 \mu \mathrm{M}$ reduced shoot proliferation, but permitted better shoot elongation. After 5 weeks in a mix of 3 peat : 2 vermiculite : 1 perlite, shoots $>20 \mathrm{~mm}$ rooted better than shoots measuring 10 to $20 \mathrm{~mm}$. Chemical names used: N-(3-methyl2-butenyl)-1-H-purine-6-amine (2iP); 1H-indole-3-acetic acid (IAA).
\end{abstract}

Annual yields of lowbush blueberry are variable in the northern area of its distribution. Losses by cold injury can reach $50 \%$ in some years. This problem could be partially overcome by the culture of selected cultivars. The propagation of highly productive cultivars is also possible by cuttings, but tissue culture may be better to increase rapidly the quantity of clones needed for release. Tissue culture plants of lowbush blueberry are known to spread faster than those of the same clones propagated by cuttings.

Tissue culture techniques have been developed for highbush (Vaccinium corymbosum L.) (Cohen, 1980; Zimmerman and Broome, 1980; Wolfe et al., 1983; Grout and Read, 1986) and rabbiteye (Vaccinium ashei Reade) (Lyrene, 1978, 1980) blueberry. Apical and lateral buds of juvenile and mature plants can be used to establish the cultures, but the age of the stock plants influences micropropagation. For example, multiple shoot formation from shoot tips taken from juvenile rabbiteye blueberry was easy and rapid (Lyrene, 1980), but growth of mature shoot explants was slow, and reversion to juvenile characteristics with vigorous growth was only occasional (Lyrene, 1981).

Shoot formation from hypocotyl or excised cotyledons of lowbush blueberry was reported by Nickerson (1978). Plantlets from bud cultures of a field-selected clone were obtained by Frett and Smagula (1983), but

Received for publication 3 Jan. 1989. Support for this project was obtained from Natural Sciences and Engineering Research Council of Canada and La Fondation de l'Université du Québec à Chicoutimi. The cost of publishing this paper was defrayed in part by the payment of page charges. Under postal regulations, this paper therefore must be hereby marked advertisement solely to indicate this fact.

${ }^{1}$ Research Assistant.

${ }^{2}$ Professor of Plant Physiology. the percentage of rooting was only $44 \%$. As shoot length plays an important role in rooting highbush blueberry shoots in vitro (Wolfe et al., 1983), insufficient shoot elongation may be the cause of low rooting percentages of lowbush blueberry. Shoot length is inversely related to the $2 \mathrm{iP}$ concentration in the culture medium of highbush blueberry (Zimmerman and Broome, 1980; Billings et al., 1988). Also, reduced levels of cytokinin (24.6 $\mu \mathrm{M} 2 \mathrm{iP})$ permit elongation of rabbiteye blueberry microshoots (Lyrene, 1978). In the case by axillary budding $(\times 3)$. of lowbush blueberry, Frett and Smagula (1983) predicted a maximum shoot length at $59 \mu$ м 2iP. The objectives of our research were to obtain rejuvenated clones from fieldgrown stock plants and to study the effect of $2 \mathrm{iP}$ concentration on shoot length and on subsequent rooting.

For the initiation phase, actively growing shoot tips (30 to $50 \mathrm{~mm}$ long) were selected from plants growing in a commercial field located in Ste Marguerite-Marie (lat. $48^{\circ} 47^{\prime} \mathrm{N}$, long. $72^{\circ} 18^{\prime} \mathrm{W}$ ) near St. John's Lake in the province of Quebec in June 1986. The shoots were sectioned into $20-\mathrm{mm}$ segments and surface-disinfected for $10 \mathrm{~min}$ in $6 \%$ calcium hypochlorite. The segments were rinsed a few seconds in sterile distilled water and soaked in a sterile solution containing $7.5 \mathrm{mg}$ citric acid and $5 \mathrm{mg}$ ascorbic acid in $100 \mathrm{ml}$ of water. Finally, the segments were rinsed twice for 10 min each time with sterile distilled water. Both ends of the segments were recut to obtain single-bud explants $6 \mathrm{~mm}$ long, including a leaf and a portion of stem. A total of 475 explants were placed on $20 \mathrm{ml}$ of Z-2 medium (Zimmerman and Broome, 1980) in 20 -mm test tubes ( 1 explant/tube). The $\mathrm{pH}$ was adjusted to 4.8 before adding sucrose (3\%) and agar (1\%). Growth regulators IAA (11.4 and $22.8 \mu \mathrm{M})$ and $2 \mathrm{iP}(49.2$ and 73.8 $\mu \mathrm{M})$ were added to the medium in a factorial combination for the first 6 weeks in culture. The cultures were grown at $23 \pm 2 \mathrm{C}$ on a shelf unit under 16-hr photoperiod (30 $\mu \mathrm{mol} \cdot \mathrm{s}^{-1} \cdot \mathrm{m}^{-2}$ at the level of the explants) using cool-white fluorescent tubes.

For the multiplication phase, only $2 \mathrm{iP}$ (59

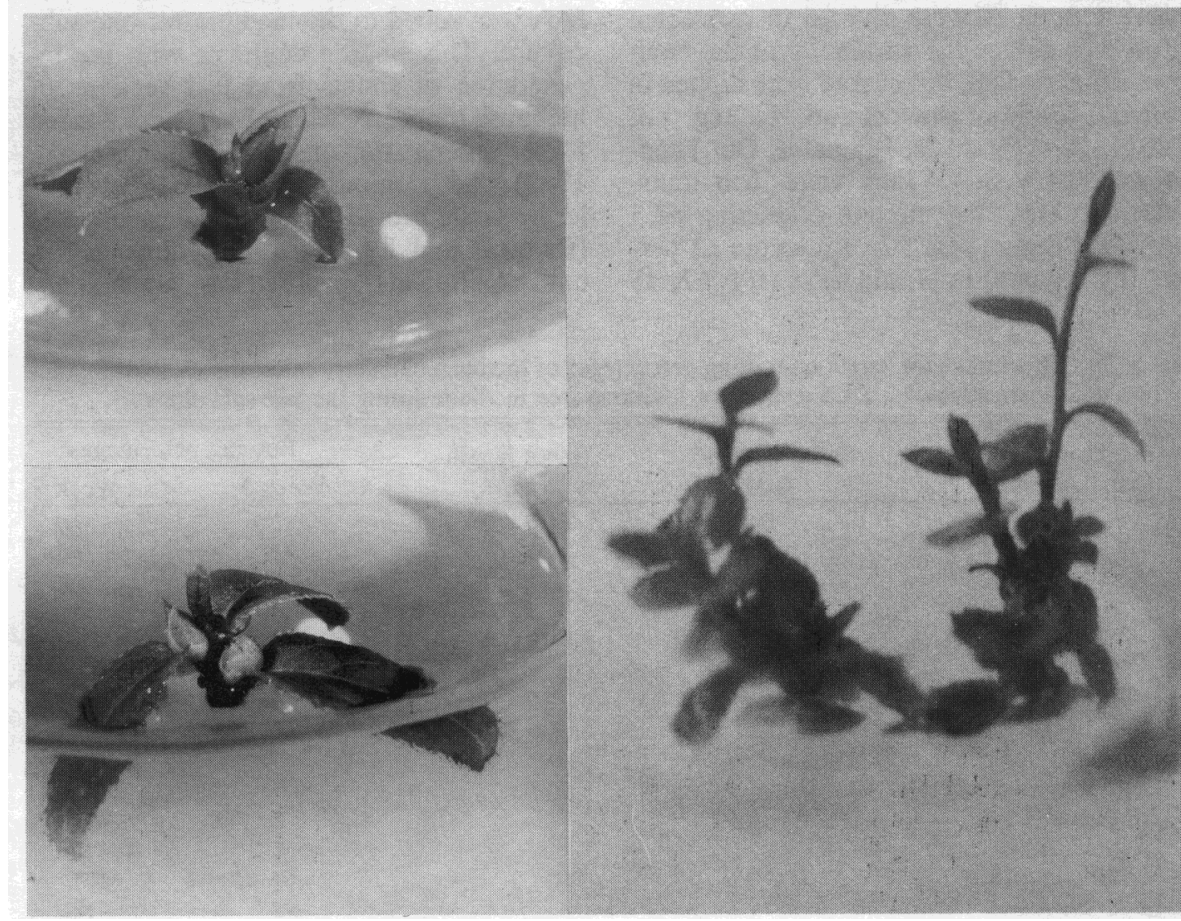

Fig. 1. (upper left) The opened axillary bud of a non-juvenile explant of lowbush blueberry after 6 weeks $(x 4)$. (lower left) Three expanded leaves of mature appearance; there is no stem elongation and the apex is dead. Two axillary buds were produced $(x 4)$. (right) Juvenile shoots proliferating 


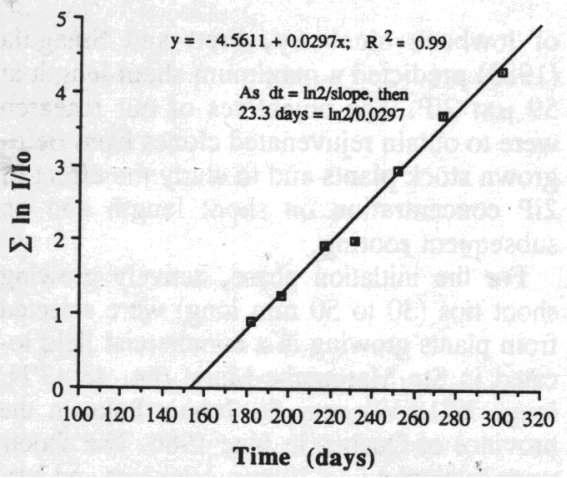

Fig. 2. Regression curve calculated from the summation of the natural logarithms of the number of shoots measured at the beginning $\left(I_{0}\right)$ and at the end (I) of each subculture of lowbush blueberry on Z-2 medium with $59 \mu \mathrm{M} 2 \mathrm{iP}$, and estimating the shoot doubling time.

$\mu \mathrm{M})$ was added to the basal medium. Subcultures were done at 3 -week intervals. The environmental conditions were similar to the initiation phase. The number of shoots was measured at the beginning and at the end of each subculture to estimate the shoot doubling time by the method of Flegman and Wainwright (1981).

For the elongation phase, shoots $(5 \mathrm{~mm}$ long) were placed on Z-2 medium with reduced cytokinin concentration $(0,12.3$, and $24.6 \mu \mathrm{M} 2 \mathrm{iP})$. The culture test tubes were maintained at room temperature under the same light regime as in the initiation phase W HPS) at $140 \mu \mathrm{mol} \cdot \mathrm{s}^{-1} \cdot \mathrm{m}^{-2}$.

For rooting studies, 160 shoots 10 to 20 $\mathrm{mm}$ long and 160 longer than $20 \mathrm{~mm}$ were harvested. They were divided in two equal groups" to reduce the variability of the environmental factors. All shoots were dipped in sterile Stim-Root powder (no. 1; Reg. no. 12011, Plant Products, Bramalea, Ont.) containing $0.1 \%$ IBA. They were then transferred to a potting mixture consisting of 3 moist sphagnum peat : 2 vermiculite : 1 perlite (by volume) in plastic trays (IPL 67, 45 or under high-pressure sodium lamps (400

$\mathrm{cm}^{3}$ each hole) and placed randomly in a rooting chamber where they were misted manually three times a day. The shoots were grown at $20 \pm 2 \mathrm{C}$ under a 18 -hr photoperiod $\left(68 \mu \mathrm{mol} \cdot \mathrm{s}^{-1} \cdot \mathrm{m}^{-2}\right.$ at the level of the trays) using cool-white fluorescent tubes. The microcuttings were evaluated for percent rooting after 5 and 8 weeks. The data were analyzed by analysis of variance.

In the first 3 weeks after culture initiation, 222 explants out of 475 in culture were contaminated and many explants browned or became covered with callus. The leaves of 33 axillary buds expanded during the first 6 weeks. Their shape was oblong, such as mature leaves. Their development was very slow and there was virtually no internode elongation (Fig. 1, upper left). Death of the shoot apices was frequently observed, followed by the formation of axillary buds (Fig. 1, lower left). Those buds often browned before opening or again produced oblong leaves with no internode elongation. After 19 weeks, thin stems bearing small and rounder leaves were produced on two explants. One explant was initiated on the medium containing $73.8 \mu \mathrm{M}$ $2 \mathrm{iP}$ and $22.8 \mu \mathrm{M}$ IAA, and the other was initiated on the medium containing $49.2 \mu \mathrm{M}$ $2 \mathrm{iP}$ and $11.4 \mu \mathrm{M}$ IAA. The measurements of the leaves ( $3 \mathrm{~mm}$ wide, $4 \mathrm{~mm}$ long) and stems $(0.48 \mathrm{~mm})$ were similar to the measurements of tissue culture shoots of rabbiteye blueberry (Lyrene, 1981). Shoots that closely resemble new seedlings are juvenile. They were sectioned and subcultured on the multiplication medium, where they proliferated by axillary budding (Fig. 1, right). Adventitious buds were also present on callus growing on leaves touching the agar, but these buds did not elongate unless $5.7 \mu \mathrm{M}$ IAA was added to the medium for one subculture. This finding contrasts with the regeneration of shoots from leaf sections of highbush blueberry where IAA is not needed for the regeneration of shoots (Billings et al., 1988). Adventitious budding on detached leaves could provide high multiplication rates (Dweikat and Lyrene, 1988); however, in our experiments, proliferation by axillary

Table 1. Effect of shoot length on rooting percentages of lowbush blueberry microshoots grown under two light intensities with $24.6 \mu \mathrm{m} 2 \mathrm{iP}$ or hormone-free medium during the last subculture.

\begin{tabular}{|c|c|c|c|c|}
\hline \multirow{2}{*}{$\begin{array}{c}\text { Light intensity } \\
\left(\mu \mathrm{mol} \cdot \mathrm{s}^{-1} \cdot \mathrm{m}^{-2}\right)\end{array}$} & \multirow{2}{*}{$\begin{array}{c}2 \mathrm{iP} \text { concn } \\
(\mu \mathrm{M})\end{array}$} & \multirow{2}{*}{$\begin{array}{c}\text { Shoot length } \\
(\mathrm{mm})\end{array}$} & \multicolumn{2}{|c|}{ Rooting percentages $\mathbf{z}$} \\
\hline & & & Week 5 & Week 8 \\
\hline \multirow[t]{3}{*}{140} & 0 & $\begin{array}{c}10-20 \\
>20\end{array}$ & $\begin{array}{l}52 \\
81\end{array}$ & $\begin{array}{l}67 \\
87\end{array}$ \\
\hline & 24.6 & $10-20$ & 81 & 95 \\
\hline & & $>20$ & 98 & 100 \\
\hline \multirow[t]{4}{*}{30} & 0 & $10-20$ & 52 & 79 \\
\hline & & $>20$ & 83 & 94 \\
\hline & 24.6 & $10-20$ & 65 & 85 \\
\hline & \multirow{2}{*}{\multicolumn{3}{|c|}{ Significance }} & 88 \\
\hline Light intensity (LI) & & & & \\
\hline $2 \mathrm{iP}$ concn $(\mathrm{C})$ & & & $*$ & * \\
\hline $\mathrm{LI} \times \mathrm{C}$ & & & * & NS \\
\hline Shoot length (SL) & & & $* *$ & $*$ \\
\hline $\mathrm{LI} \times \mathrm{SL}$ & & & NS & NS \\
\hline $\mathrm{C} \times \mathrm{SL}$ & & & $*$ & NS \\
\hline $\mathrm{LI} \times \mathrm{C} \times \mathrm{SL}$ & & & NS & NS \\
\hline
\end{tabular}

${ }^{2}$ Rooting percentages were measured 5 and 8 weeks after dipping the microshoots in $0.1 \%$ IBA. Ns, ****Not significant or significant at $P=0.05$ or 0.01 , respectively.
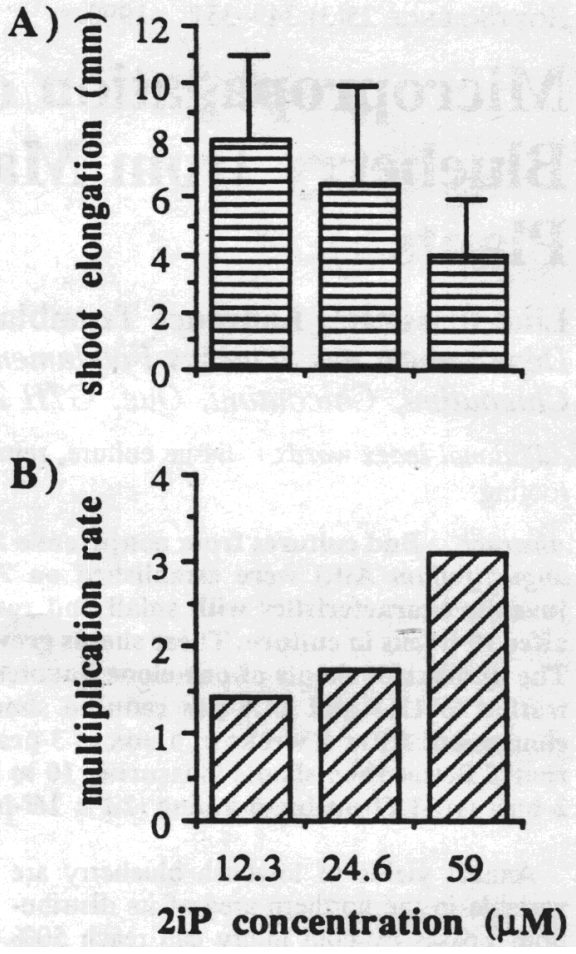

Fig. 3. Effect of 2iP concentration on (A) shoot elongation and (B) multiplication rate of lowbush blueberry. Data (A) are means $( \pm \mathrm{SD})$ for 20 shoots.

budding was preferred over adventitious budding on leaf callus because the genetic stability of the adventitious system has not been verified (Cohen, 1980). The shoot doubling time of clone $\mathrm{B}$ was measured from week 26 to week 43 after the initiation of the cultures (Fig. 2). The number of shoots of lowbush blueberry doubled every 23.3 days. This result compares to the best doubling times obtained with raspberry (Desjardins and Gosselin, 1987).

Shoot elongation was promoted by reducing the concentration of $2 \mathrm{iP}$ to $24.6 \mu \mathrm{M}$, but the microshoots were not long enough to be rooted after one subculture ( 3 weeks). When shoots were left on the same medium without transfer for 3 to 6 additional weeks, proliferation slowed down and the shoots elongated. In the absence of $2 \mathrm{iP}$, the microshoots elongated, but proliferation stopped. After 3 weeks, yellow and red spots were present on leaves, and the shoots appeared to be unhealthy. In another experiment, $12.3 \mu \mathrm{M} 2 \mathrm{iP}$ was compared to 24.6 and $59 \mu \mathrm{M} 2 \mathrm{iP}$ for their effects on shoot elongation (Fig. 3). The first one was the best concentration tested to obtain longer shoots rapidly, without the problem of yellowing of cultures observed in the hormone-free medium.

The microshoots were rooted in June 1987. The best results were obtained with shoots pretreated under high light intensity, on 24.6 $\mu \mathrm{M} 2 \mathrm{iP}$, and $>20 \mathrm{~mm}$ (Table 1). High light intensity influenced the rapidity of rooting, as percentages $>90 \%$ could be obtained after 5 weeks, whereas the same percentages were obtained only after 8 weeks when the shoots 


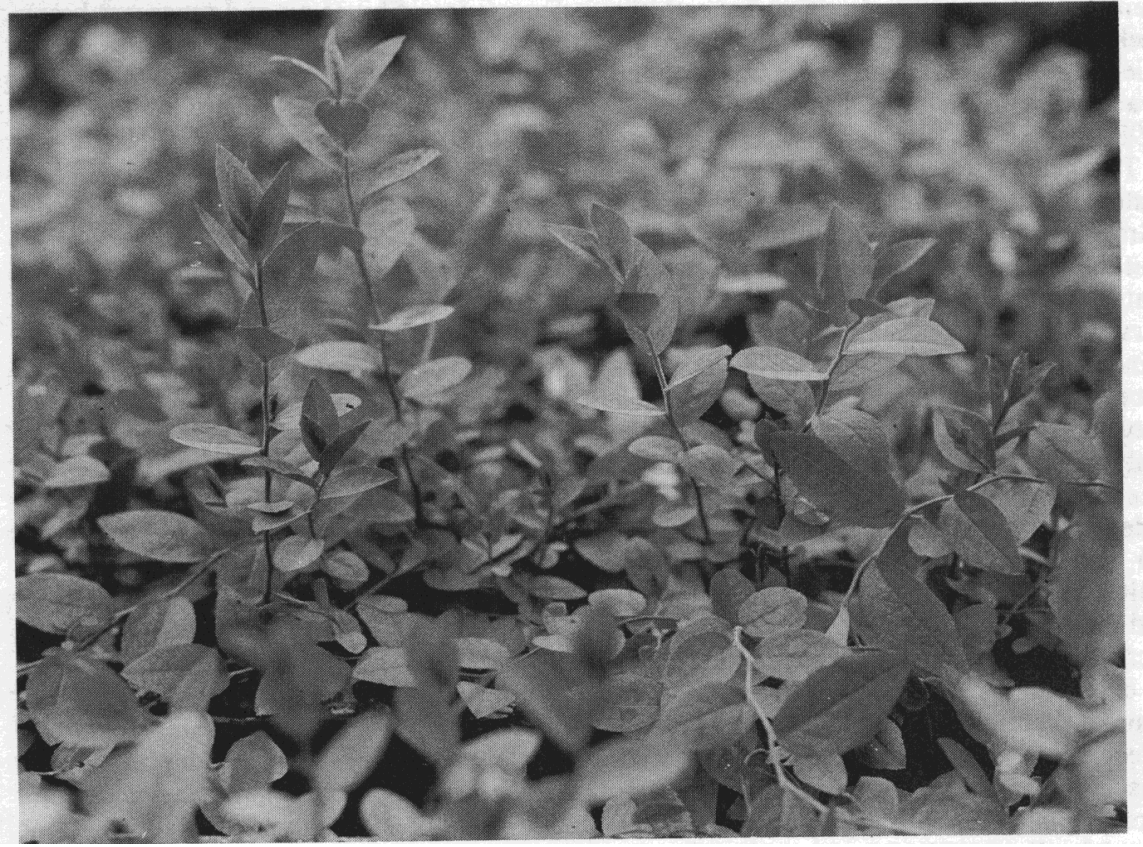

Grout, J.M. and P.E. Read. 1986. Influence of stock plant propagation method on tissue culture and leaf-bud propagation of 'Northblue' blueberry. J. Amer. Soc. Hort. Sci. 111:368371

Lyrene, P.M. 1978. Blueberry callus and shoottip culture. Proc. Fla. State Hort. Soc. 91:171172

Lyrene, P.M. 1980. Micropropagation of rabbiteye blueberries. HortScience 15:80-81.

Lyrene, P.M. 1981. Juvenility and production of fast-rooting cuttings from blueberry shoot cultures. J. Amer. Soc. Hort. Sci. 106:396-398.

Nickerson, N.L. 1978. In vitro shoot formation in lowbush blueberry seedling explants. HortScience 13:698.

Wolfe, D.E., P. Eck, and C.-K. Chin. 1983. Evaluation of seven media for micropropagation of highbush blueberry. HortScience 18:703705.

Zimmerman, R.H. and O.C. Broome, 1980. Blueberry micropropagation, p. 44-47. In: R.H. Zimmerman (ed.). Proc. of the Conf. on Nursery Production of Fruit Plants through Tissue Culture-Applications and Feasibility. USDASEA, Agr. Res. Results ARR-NE-11.

Fig. 4. Rooted plantlets 4 months after transfer to soil $(\times 0.5)$.

did not receive a high light intensity pretreatment. The concentration of $2 \mathrm{iP}$ in the medium at the last subculture should be low to obtain longer shoots which root more easily. The plantlets grew well after they were rooted (Fig. 4). They were put in a cold frame during Fall 1987 and transferred to a greenhouse in the spring. They produced normal flowers and fruits in Summer 1988.

Growth of mature explants of lowbush blueberry in vitro was rare, but, when reversion to juvenile characteristics occurred, proliferation was rapid. At $59 \mu \mathrm{M}, 2 \mathrm{iP}$ was good for shoot proliferation, but the microshoots remained too short' for rooting. Reduction of the cytokinin level in the last subculture before rooting permitted shoot elongation and facilitated rooting. Efforts should be directed toward the improvement of the initiation phase, as this is the limiting step.

\section{Literature Cited}

Billings, S.G., C.K. Chin, and G. Jelenkovic. 1988. Regeneration of blueberry plantlets from leaf segments. HortScience 23:763-766.

Cohen, D. 1980. Application of micropropagation methods for blueberries and tamarillos. Proc. Intl. Plant Prop. Soc. 30:144-146.

Desjardins, Y. and A. Gosselin. 1987. Influence des concentrations hormonales, du milieu de culture et d'un anti-oxydant sur le temps de doublage des tiges de framboisiers "Madawaska" cultivés in vitro. Can. J. Plant Sci. 67:863-869.

Dweikat, I.M. and P.M. Lyrene. 1988. Adventitious shoot production from leaves of blueberry cultured in vitro. HortScience 23:629.

Flegmann, A.W. and H. Wainwright. 1981. Shoot doubling time: A quantitative parameter for characterizing shoot cultures in vitro. Plant Cell Tissue \& Organ Cult. 1:85-92.

Frett, J.J. and J.M. Smagula. 1983. In vitro shoot production of lowbush blueberry. Can. J. Plant Sci. 63:467-472.

HORTSCIENCE 25(3):351-353. 1990

\title{
Observations on the Relationships among Seed Number, Fruit Calcium, and Senescent Breakdown in Apples
}

\author{
W.J. Bramlage, S.A. Weis, and D.W. Greene \\ Department of Plant and Soil Sciences, University of Massachusetts, \\ Amherst, MA 01003
}

Additional index words. Malus domestica, naphthaleneacetic acid, gibberellin, 6benzylaminopurine

Abstract. In a population of 'Delicious' apples (Malus domestica Borkh.) with varying seed number at harvest, fruit size and Ca concentration in fruit increased with seed number. Neither $\mathrm{K}$ nor $\mathrm{Mg}$ concentration in fruit was related to seed number. In another population of 'McIntosh' apples from 50 commercial orchard blocks, the percentage of fruit that developed senescent breakdown, a Ca-deficiency disorder, decreased linearly as seed number per fruit increased. Low seed number is probably a factor contributing to Ca deficiency in apple fruit.

Previously, we reported that spraying 'McIntosh' apple trees with gibberellins $\mathrm{A}_{4}$ $\left(\mathrm{GA}_{4+7}\right)$ and N-(phenylmethyl)-1H-purine-6amine (BA) 17 days after full bloom resulted in decreased $\mathrm{Ca}$ concentrations in mature fruit as growth regulator concentrations increased (Greene et al., 1982). Looney (1979) reported similar findings with 'Spartan' apples

Received for publication 3 Jan. 1989. Massachusetts Agr. Expt. Sta. Paper 2916, This research was supported in part by Expt. Sta. projects 497 and 517. The cost of publishing this paper was defrayed in part by the payment of page charges. Under postal regulations, this paper therefore must be hereby marked advertisement solely to indicate this fact. and attributed the lower Ca concentration to the diluting effect of increased fruit size. In our study, we recorded increasing numbers of seedless fruit and increasing incidences of senescent breakdown (a Ca-deficiency disorder), along with decreasing $\mathrm{Ca}$ concentration, as $\mathrm{GA}_{4+7}$ and $\mathrm{BA}$ concentrations increased. Since parthenocarpic apples tend to be Ca-deficient (Bangerth, 1976), seed number may be a factor in determining $\mathrm{Ca}$ concentration in fruit at harvest. However, because our fruit had been sampled for mineral analyses without regard for seed number and with avoidance of fruit with breakdown, interrelationships among seed number, fruit $\mathrm{Ca}$, and senescent breakdown could not be tested. 